\title{
Recent Development of Steam Turbines with High Steam Temperatures*
}

\author{
Hideo NOMOTO**, Yoshikazu KUROKI***, Masafumi FUKUDA*** \\ and Shinya FUJITSUKA**
}

\begin{abstract}
Power plants with high thermal efficiency are essential and indispensable in order to decrease the impact on the environments. In order to achieve this goal, enhancement of the steam conditions is the most fundamental and effective measure. Recent steam conditions in Japan range from 593 to 610 degree $\mathrm{C}$ owing to the technological development. There are many areas of technology for the realization of such steam conditions, for instance, material development, cooling design, steam path development, casing design, and so on. Not only the research and development but also accumulation of the operational results is of importance to achieve a breakthrough in turbine design. In this paper, recent development of steam turbines with high temperatures will be presented focusing on their design features including material selections. This paper also deals with further efforts targeting even higher steam conditions, which are promising for future development of steam turbine technology.
\end{abstract}

Key Words: Steam Turbine, Steam Condition, High Temperature, Thermal Efficiency

\section{Introduction}

Energy saving and environmental protection are becoming more and more important for the society. In particular, emission of carbon dioxide, which causes warming of the earth, is one of the major issues for future generation. Furthermore, it is expected that we will encounter the shortage of oil and liquid natural gas in the near future. On the contrary, energy consumption will continuously increase because of the industrialization and improvement of human life. Recently, many new energy resources, which are friendly to environment, have been advocated and made applicable to power generation. They are, for instance, wind energy, fuel cells, and bio-energy and so on, and they are getting more important role in power generation as a clean energy. However, even though these energy resources are very promising, their capacity is not yet enough to cover tremendous demand from our society and need more development. Nuclear energy is an

${ }^{*}$ Received 28th September, 2005 (No. 05-4177)

** Toshiba Corporation, Keihin Product Operations, 2-4 Suehiro-cho, Tsurumi-ku, Yokohama, Kanagawa 230 0045, Japan. E-mail: hideo1.nomoto@toshiba.co.jp

*** Toshiba Corporation, Industrial and Power Systems \& Services Company, 1-1-1 Shibaura, Minato-ku, Tokyo 1058001, Japan unparalleled energy resource due to its large capacity, and does not have any emission of carbon dioxide meaning environmentally friendly in this regard. However, biggest issue of nuclear energy is how to get approval of people concerning its safety assessment. As a matter of fact, construction of new nuclear power station is difficult in most of countries, or even if it is possible, it takes a long period. Combined cycle has a high thermal efficiency, and takes considerably short time for its construction. Gas turbine technology such as cooling and material has developed rapidly due to a big demand of combined cycle, and its capacity has become larger. No doubt, it is the most promising option of power generation from viewpoints of efficiency, capacity, cycle time of construction, and initial investment. However, there is a risk of energy shortage if power generation depends on combined cycle too much, in other words, too much dependence of energy resource on natural gas.

As far as the diversity of energy resource is concerned, not only the renewable energy but also coal is one of the major candidates because its estimated amount of deposit is fairly large. Another point is that coal fired plants have a long history and its technology is well proven. Major remaining issue is the emission of carbon dioxide. In order to make the impact of coal fired plant on environment as least as possible, it is essential to raise 
the thermal efficiency and install more sophisticated environmental protection facilities. In this paper, we deal with the former task, enhancement of the plant efficiency. The most primary measure to have higher efficiency is to raise steam conditions. Steam turbine engineers have spent much time to realize it conducting study on material, cooling, blade design and so on. Japanese utilities and steam turbine manufacturers have been focused their efforts on higher seam conditions because there is no domestic energy resource and because population density is very high in Japan. Therefore, recent development and future direction of enhancement of steam turbines will be discussed in this paper.

\section{Trend of Raising Steam Conditions}

\subsection{Transition of pressure and temperature}

Figure 1 shows the recent temperature improvements in Japanese thermal power plants for about twenty years. The standard steam conditions for large fossil-fueled steam plant were $24 \mathrm{MPa}, 538 / 566$ degree $\mathrm{C}$ until early 1990s. Since then effort has been made in order to achieve higher efficiency. The improvement of main steam temperature and reheat steam temperature has become a reality by turns. In fact, main steam was raised to 566 degree $\mathrm{C}$ at the beginning of 1990s, and reheat steam was raised to 593 degree $\mathrm{C}$ at the middle of 1990 s, and again main steam achieved 593 degree $C$ in late 1990s. This concept of raising temperature in a stepwise manner enabled to keep reliability as much as possible, and made cycle time of research and development as short as possible since we could make the best use of proven technology. Being supported by material development, design tools, and operational experience, steam temperature in Japanese steam plant reached $610 \mathrm{C}$ at the beginning of this century. An important aspect of this improvement is that raising of reheat steam temperature has been always realized prior to that of main steam. This is because the increase of reheat

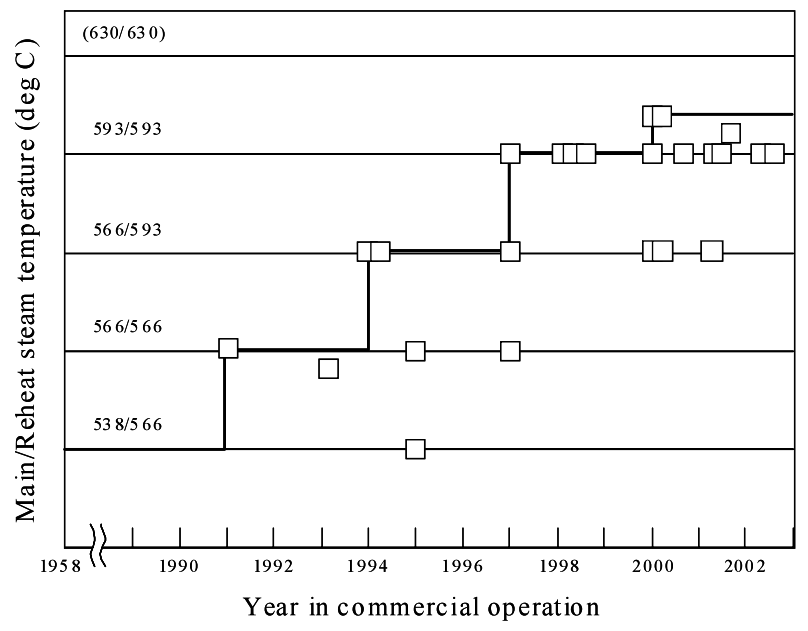

Fig. 1 Improvement of steam temperatures steam temperature is easier than that of main steam temperature and because the cost impact on initial investment of power plant is lighter. Table 1 is the list of steam turbines our company has manufactured whose temperatures of main steam and reheat steam are higher than 566 degree $\mathrm{C}$, and these turbines are included in Fig. 1. It should be emphasized that total number of the units in this table is eighteen, which is overwhelming number as a turbine manufacturer. Some of the epoch making turbines among them are as follows. Kawagoe $700 \mathrm{MW}$, whose pressure is $31 \mathrm{MPa}$, and temperatures are $566 / 566 / 566 \mathrm{de}-$ gree $\mathrm{C}^{(1),(2)}$. Nanao $700 \mathrm{MW}$ has temperatures of 593/593 degree $\mathrm{C}$ both for main steam and reheat steam. Temperatures of Hekinan No.4 and No.5 are 566/593 degree C, and their capacity is $1000 \mathrm{MW}$, which is the largest one in the world as a $60 \mathrm{~Hz}$ tandem-compound turbine.

\subsection{Material improvement}

Material development is the most critical technology to achieve temperature improvement of steam turbines. This is because steam turbines do not use complicated cooling technology compared with gas turbines, resulting in primary focus on the development of heat-resistant material. Three kinds of materials, termed as $12 \% \mathrm{Cr}$ rotor steel, Modified 12\% Cr steel and New 12\% Cr steel in this paper, were developed by our company in order to raise temperatures from 566 degree $\mathrm{C}$ to 610 degree $\mathrm{C}$ in the past. The comparison of creep rupture strength is shown in Fig. 2 together with conventional 1\% CrMoV material, and typical chemical composition of each material is in Table 2. In order to make the design of steam turbines for 566 degree $\mathrm{C}$ possible, $12 \% \mathrm{Cr}$ rotor steel was improved

Table 1 Manufacturing experience of high temperature turbines

\begin{tabular}{|c|c|c|}
\hline Capacity & $50 \mathrm{~Hz}$ & $60 \mathrm{~Hz}$ \\
\hline Less than 500MW & 4 & 0 \\
\hline $\begin{array}{c}\text { More than 500MW } \\
\text { and less than 700MW }\end{array}$ & 1 & 9 \\
\hline More than 700MW & 1 & 3 \\
\hline
\end{tabular}

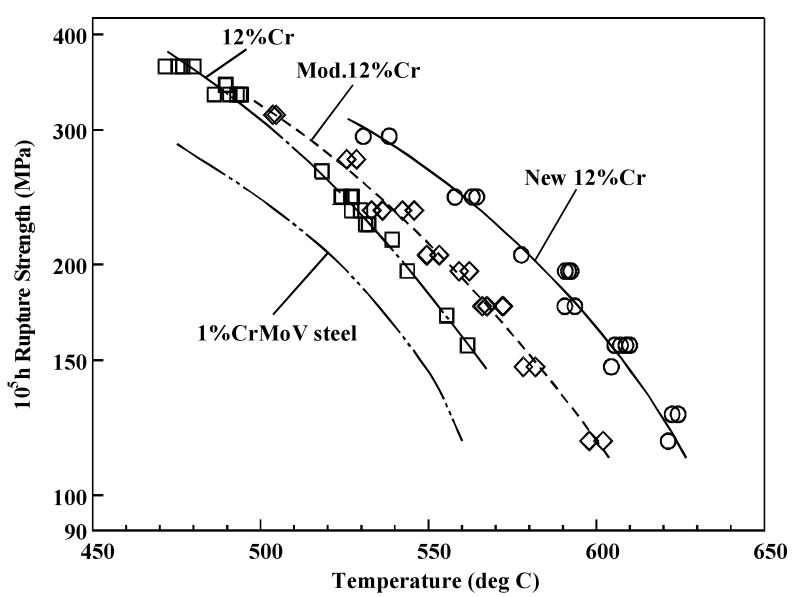

Fig. 2 Comparison of rupture strength 


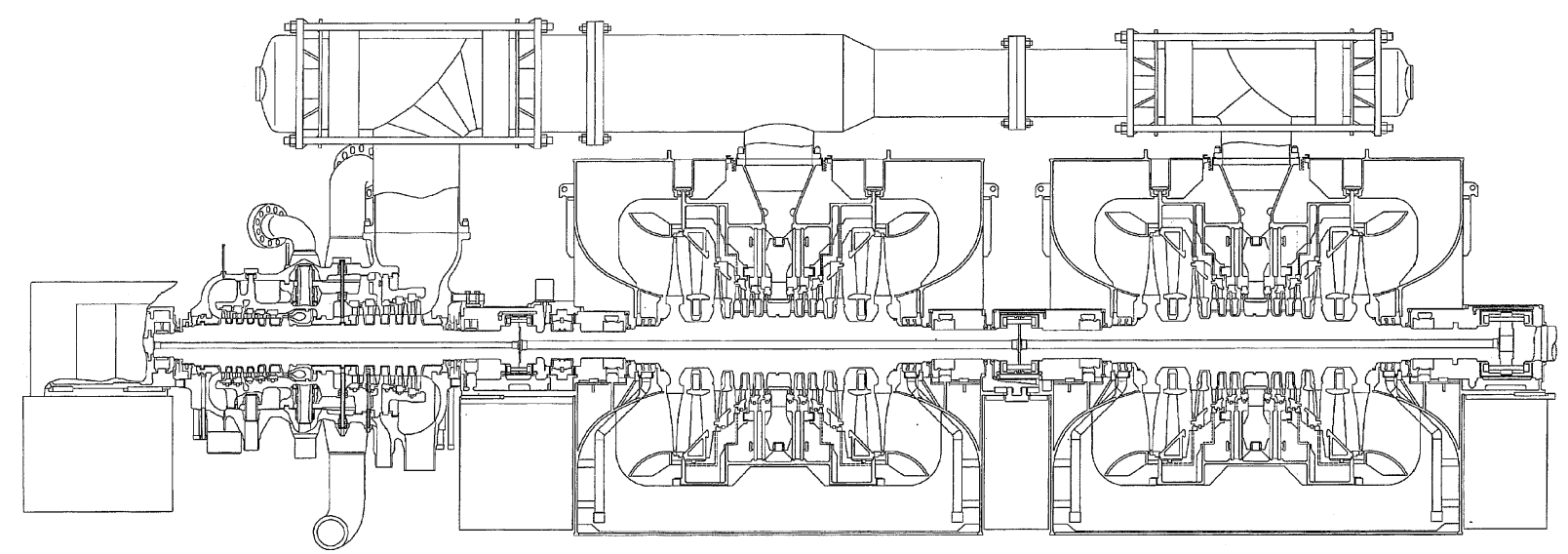

Fig. 3 Cross section of $700 \mathrm{MW}$ steam turbine

Table 2 Chemical composition of rotor material

\begin{tabular}{|l|c|c|c|c|c|c|c|c|c|c|c|c|c|}
\hline & $\mathrm{C}$ & $\mathrm{Si}$ & $\mathrm{Mn}$ & $\mathrm{Ni}$ & $\mathrm{Cr}$ & $\mathrm{Mo}$ & $\mathrm{V}$ & $\mathrm{Nb}$ & $\mathrm{N}$ & $\mathrm{W}$ & $\mathrm{Co}$ & $\mathrm{B}$ & $\mathrm{Fe}$ \\
\hline $12 \% \mathrm{Cr}$ & 0.18 & 0.20 & 0.7 & 0.4 & 11.0 & 1.00 & 0.2 & 0.07 & 0.05 & - & - & - & Bal. \\
\hline Mod. $12 \% \mathrm{Cr}$ & 0.14 & 0.05 & 0.6 & 0.7 & 10.0 & 1.00 & 0.2 & 0.05 & 0.05 & 1.0 & - & - & Bal. \\
\hline New $12 \% \mathrm{Cr}$ & 0.11 & 0.08 & 0.1 & 0.2 & 9.7 & 0.65 & 0.2 & 0.05 & 0.02 & 1.8 & 3.0 & 0.01 & Bal. \\
\hline
\end{tabular}

from H46 alloy steel for gas turbines. The characteristic of this material is the precipitation strengthening with $\mathrm{Nb} / \mathrm{Ta}$ carbo-nitride and VC carbides in tempered martensite. This steel was used widely to cope with the steam temperature of 566 degree C. However, after accumulating experience and confirming reliability of steam turbines with temperature of 566 degree C, steam turbine designers and metallurgist pursued more improvement. In 1980s, this effort led to the development of Modified 12\% Cr rotor steel, and it aimed at steam temperature of 593 degree C. Tungsten of about $1 \%$ weight is included in this material, resulting in raising creep rupture strength as is shown in Fig. 2 thanks to the effect of solid-solution strengthening and precipitation with carbides. Further effort was continued in the world, and during the 1990s, there was more advance in $9-12 \% \mathrm{Cr}$ steels. Reflecting the research activity in these days, we developed New $12 \% \mathrm{Cr}$ rotor steel, whose chemical composition is also listed in Table 2. Tungsten was increased and cobalt and boron were added. Due to the effect of higher tungsten content, intermetallic compound increases, contributing to precipitation strengthening. Cobalt represses formation of delta ferrite, and boron improves creep rupture strength since it enforces grain boundary even though its amount is small. Similar efforts have been also made for bucket material, casing, and valve material as well. Even though some different aspects for bucket and casing materials must be taken into consideration, basic concept such as chemical composition and effect of each added composition are similar. Table 3 shows candidate materials applied to major turbine parts depending on temperature range. In particu-
Table 3 Candidate materials for each temperature

\begin{tabular}{|l|c|c|c|c|}
\hline $\begin{array}{l}\text { Temp. } \\
\text { Parts }\end{array}$ & $566 \mathrm{deg} \mathrm{C}$ & $593 \operatorname{deg} \mathrm{C}$ & $610 \operatorname{deg} \mathrm{C}$ & $630 \operatorname{deg} \mathrm{C}$ \\
\hline Rotor & $12 \% \mathrm{Cr}$ & $\mathrm{Mod} .12 \% \mathrm{Cr}$ & New $12 \% \mathrm{Cr}$ \\
\hline Bucket & $12 \% \mathrm{Cr}$ & Mod. $12 \% \mathrm{Cr}$ & New $12 \% \mathrm{Cr}$ \\
\hline Casting & $1 \mathrm{Cr}-\mathrm{Mo}-\mathrm{V}$ & $12 \% \mathrm{Cr}$ & Mod.12\% Cr $\mathrm{New} 12 \% \mathrm{Cr}$ \\
\hline
\end{tabular}

Table 4 Specifications of the turbine

\begin{tabular}{|c|c|}
\hline Type & TC4P-40inches \\
\hline Capacity & $700 \mathrm{MW}$ \\
\hline Steam Conditions & $24.1 \mathrm{MPa}, 593 / 593$ degree C \\
\hline Exhaust Vacuum & $722 \mathrm{mmHg}$ \\
\hline Speed & $3,600 \mathrm{rpm}$ \\
\hline Number of Casings & $1-$ HP-IP Section \\
& 2 -LP Sections \\
\hline Number of Stages & $1 \times 6$ stages HP Section \\
& $1 \times 5$ stages IP Section \\
& $4 \times 5$ stages LP Section \\
\hline
\end{tabular}

lar, New $12 \% \mathrm{Cr}$ steels can be applicable to the temperature of 630 degree $\mathrm{C}$ showing their capability for further improvement of the steam turbine efficiency.

\section{Design Features of Recent High Temperature Steam Turbines}

\subsection{Specifications of the turbine}

Many high temperature turbines have been put in service past twenty years in Japan, and most of them are large size machines ranging from $500 \mathrm{MW}$ to $1000 \mathrm{MW}$ as was discussed. Among them, the focus will be put on typical $700 \mathrm{MW}$ steam turbines in this paper because their unit numbers is by far the largest since their rated output is suitable for Japanese grid capacity. Table 4 shows the specification of the turbine, Fig. 3 is its cross section, 
Table 5 Material selection

\begin{tabular}{|c|c|}
\hline HIP Rotor & $\begin{array}{c}12 \% \mathrm{CrMoVNbNW} \\
\text { (Modified 12\%Cr) }\end{array}$ \\
\hline LP Rotor & $\begin{array}{c}3.5 \% \text { NiCrMoV } \\
\text { (Super Clean) }\end{array}$ \\
\hline Moving Blades & $\begin{array}{c}12 \% \mathrm{CrMoVNbNW} \\
\text { (Modified 12\%Cr) } \\
\text { and others }\end{array}$ \\
\hline Main Steam Flange \& Elbow & $\mathbf{9 \% C r M o V N b N ( O n e - P i e c e ) ~}$ \\
\hline HIP Outer Casing & $12 \%$ CrMoVNbN \\
\hline HP Inner Casing & $12 \%$ CrMoVNbN \\
\hline IP Inner Casing & CrMo \\
\hline Nozzle Box & $9 \%$ CrMoVNbN \\
\hline
\end{tabular}

and Table 5 is the selection of materials. It is tandem compound type and has three casings. The main steam pressure is $24.1 \mathrm{MPa}$, temperatures are 593/593 degree C for main steam and reheat steam respectively. The revolutional speed is $3600 \mathrm{rpm}$ and the last stage blade is 40 inches titanium blade with ample operational experience.

\subsection{Features of high pressure section and interme- diate section}

High pressure section and intermediate pressure sections are opposed-flow type, and this configuration has a couple of advantages. First, we can have the total length of the turbine as short as possible, making not only turbine cost but also building cost lower. Secondly, thrust design is easier because steam expands in opposed directions. Thirdly, blade height of intermediate section will be longer than double flow design, making the secondary loss of the blade smaller. Originally, $700 \mathrm{MW}$ turbines had single flow high pressure section and double flow intermediate section. However, due to the technology development and accumulation of design experience, we could achieve more compact design of opposed flow HP-IP section. Modified $12 \% \mathrm{Cr}$ material is used for high pressure and intermediate pressure rotor since both main steam and reheat steam temperatures are 593 degree C. Buckets of former stages of both sections are also made of Modified $12 \% \mathrm{Cr}$ material for the same reason. Both main steam and reheat steam enter from upper half and lower half. This construction is beneficial because transient casing deformation during start up can be kept as small as possible. The flange and elbow for main steam is mono block and made of $9 \% \mathrm{Cr}$ steel. The casing of high pressure and intermediate pressure sections are double shell construction in order to endure pressure difference between steam path and atmosphere. $12 \% \mathrm{Cr}$ cast steel is used for the inner casing of high pressure section and outer casing of these sections. One of the considerations to cope with high reheat steam temperature is that high pressure inner casing is extended to enclose reheat steam inlet applying double shell construction to reheat bowl as well. High pressure section has six stages and intermediate section has five stages in order to achieve optimum efficiency.

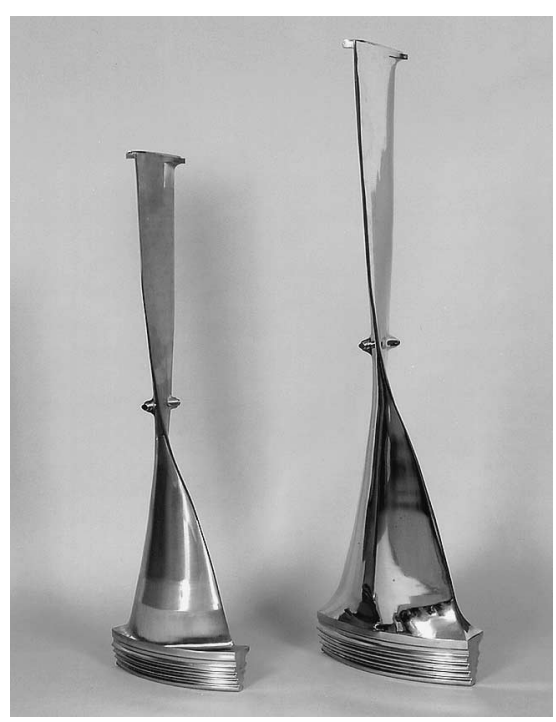

Fig. 4 Last stage blades

\subsection{Low pressure section}

The turbine has two low-pressure casings. Rotor material is $3.5 \%$ NiCrMoV steel, which has enough capability including ductility against large centrifugal force and ductility. The exhaust hood has a curvature in order to realize low hood loss. This configuration was optimized both from computed fluid dynamics and experiment. The most important feature of low pressure section is, naturally, the last stage blade. In this turbine, 40 inches titanium blade is adopted. This titanium blade for $3600 \mathrm{rpm}$ was developed late 1980s, and has been used for $700 \mathrm{MW}$ and $1000 \mathrm{MW}$ coal fired turbines and for $80 \mathrm{MW}$ turbines for combined cycle. Though this blade is well proven due to long operating experience, titanium had an impact on cost of turbine. For this reason, we developed new 40 inches last stage blade for $3600 \mathrm{rpm}$ and 48 inches blade for $3000 \mathrm{rpm}$ using conventional $12 \% \mathrm{Cr}$ steel recently. They are shown in Fig. 4. The new 40 and 48 inches blade have similar configuration making the best of titanium 40 inches blade experience, and recent progress of fluid dynamics and mechanical design were added ${ }^{(4)}$.

\section{4 Steam path}

Not only improvement of steam conditions but also higher internal efficiency is important. State-of-art design is applied to steam path thanks to the recent development of computer fluid dynamics. Figure 5 shows typical stationary blade and bucket. As is shown in the figure, these blades are three dimensionally designed in order to repress secondary loss at the root area and tip area. And also, area distribution in radial direction is optimized taking account of loss distribution and leakage loss at the root and tip. Another feature of the steam path is the wide adoption of integral snubber at the tip, which connects all the blades circumferentially as is shown in Fig. 6. This design was introduced from gas turbine design and has a couple of 


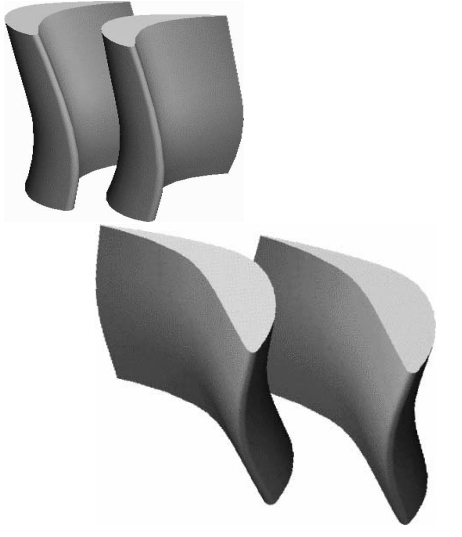

Fig. 5 Steam path

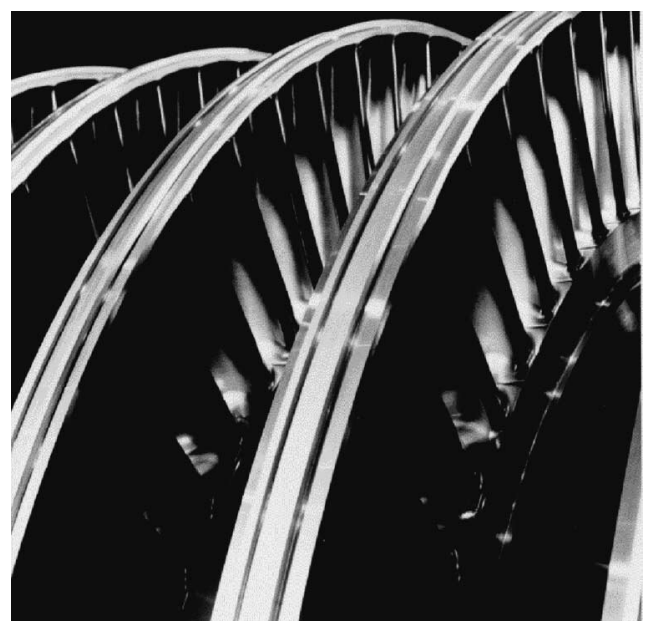

Fig. 6 Rotor with snubber blades

advantages. First one is vibration control. Since all the blades are connected together at rated speed, its vibration response is lower than grouped blades. Secondly, this design has better leakage control at the tip because there is no circumferential clearance between blades. Thirdly, it is very easy to assemble and disassemble because chalking is not necessary.

\section{Further Improvement of Steam Conditions in Fu- ture}

\subsection{Evaluation of steam conditions and candidate materials}

Based on the experience we obtained by designing and producing actual machines with high temperatures, study was conducted to find the direction of further improvement. Table 6 shows cases we studied together with candidate materials of critical components. Two options were studied, Case 1 is 630/700 degree C, Case 2 is $700 / 700$ degree C. Main steam pressure is $25 \mathrm{MPa}$ and turbine output is $500 \mathrm{MW}$ for both cases. Reference steam conditions are 600/600 degree $\mathrm{C}$, and it can be designed using proven technology because these temperatures are within experience. High pressure section of Case 1 can be
Table 6 Candidate steam conditions

\begin{tabular}{|c|c|c|c|}
\hline & Reference & Case1 & Case2 \\
\hline Main Steam Temperature & $600 \mathrm{deg} \mathrm{C}$ & $630 \mathrm{deg} \mathrm{C}$ & $700 \mathrm{deg} \mathrm{C}$ \\
\hline Reheat Steam Temperature & $600 \mathrm{deg} \mathrm{C}$ & $700 \mathrm{deg} \mathrm{C}$ & $700 \mathrm{deg} \mathrm{C}$ \\
\hline Main SteamPressure & $25 \mathrm{MPa}$ & $25 \mathrm{MPa}$ & $25 \mathrm{MPa}$ \\
\hline Reheat SteamPressure & $5 \mathrm{MPa}$ & $5.5 \mathrm{MPa}$ & $5.5 \mathrm{MPa}$ \\
\hline $\begin{array}{c}\text { Rrelative Improvement of } \\
\text { Thermal Efficiency }\end{array}$ & Base & 1.03 & 1.047 \\
\hline HP turbine Material & $12 \% \mathrm{Cr}$ & $12 \% \mathrm{Cr}$ & $\mathrm{Ni}$ base \\
\hline IP turbine Material & $12 \% \mathrm{Cr}$ & $12 \% \mathrm{Cr}$ & $12 \% \mathrm{Cr}$ \\
\hline Valve Material & $12 \% \mathrm{Cr}$ & $12 \% \mathrm{Cr}$ or Ni base & Ni base \\
\hline
\end{tabular}

designed without any major research and development because New $12 \% \mathrm{Cr}$ steel can cover this temperature as was discussed. As for intermediate section, steam temperature is 700 degree $\mathrm{C}$, and it is beyond the experience of using ferrite rotor material. However, cooling technology can be applicable to intermediate section, which will be discussed more in detail later. Ni base material is necessary for some components, but they are limited.

On the other hand, temperature of main steam for Case 2 will require Ni base material in a wide range. Especially, the rotor material of the HP section, which is biggest component of rotational parts in this section, will be Ni base material. There are some candidates of $\mathrm{Ni}$ base materials based on gas turbine technology, but much research work is inevitable to prove the quality of large forging for steam turbine rotor. Alternative method is to design welded rotor connecting Ni base material and $12 \%$ $\mathrm{Cr}$ material, making $\mathrm{Ni}$ base forging as small as possible. But this measure also needs research activity of welding between two different materials. Second alternative is to use cooling technology. According to our study, internal cooling making use of steam after the first stage is not enough in order to decrease rotor temperature. This leads to the external cooling extracting cooling steam from boiler. This makes cooling system rather complicated because high pressure section has double shell construction and because casings has thick wall in order to contain high pressure steam. These cause rather long research period for steam turbine. Another important point we should take into consideration is the evaluation of initial investment including efficiency gain. Raising main steam temperature has much bigger impact than reheat temperature on economics of plant operation. Therefore, we concluded that Case 1 is much attractive as the reheat temperature was always improved prior to main steam in the past.

\section{2 Conceptual design of critical components}

The cross section of the intermediate pressure turbine for Case 1 is shown in Fig. 7, which requires more research and development work than high pressure section for this case. Reheat steam of 700 degree $\mathrm{C}$ flows into the turbine from four inlet pipes located on upper half and lower half. In order to avoid direct contact of inlet steam from outer casing, inlet pipes have inner pipe and outer pipe. 


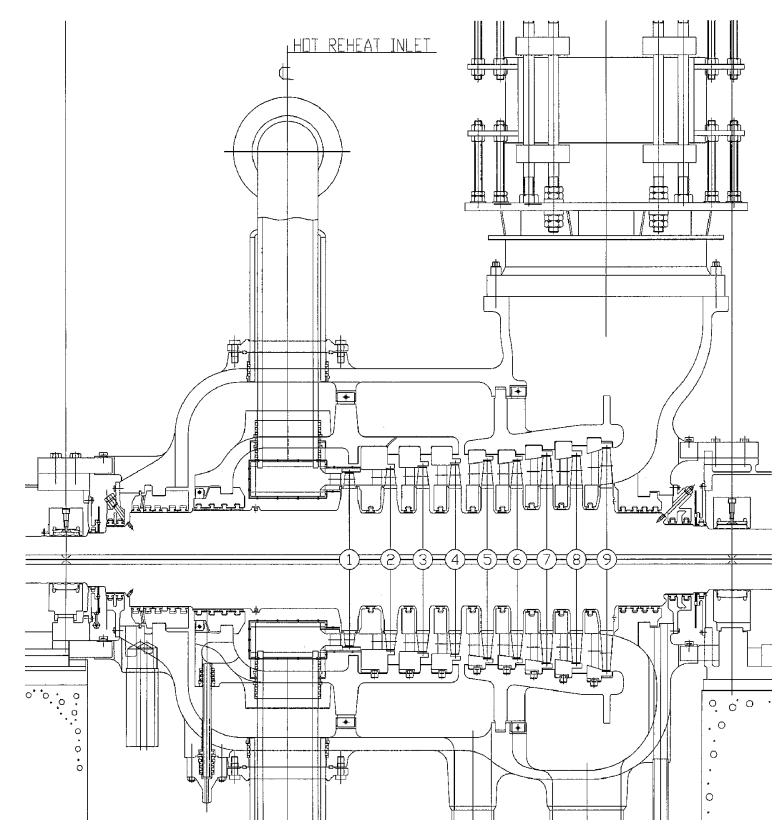

Fig. 7 Cross section of intermediate pressure turbine

This concept has been already adopted for main steam improvement and is well proven design, and inner pipe is made of Ni base material. Reheat steam flows to nozzle casing, which is also made of Ni base material, through inlet pipe. This nozzle casing is a very important feature of this section. It is similar to nozzle box in current steam turbines, which prevent main steam of high pressure and temperature from contacting other area and provides nozzle governing operation. However, the purpose of nozzle casing in this turbine is to simply enclose the steam in limited area where Ni base material is adopted, and nozzle governing function is not necessary. Ni base material will be applied to buckets of former stages in this section, for instance from the first to the third stages. Inner inlet pipe, nozzle casing, and former stage buckets are extremely important parts since they contact with high temperature steam, but fortunately, they are rather small parts. This is very important point because Ni base material is widely used in gas turbine, but the product is small. Therefore, if the adoption of $\mathrm{Ni}$ base material is limited to these important but small parts, it will shorten research and development period and save its investment. Then, the most important part from this point of view is apparently rotor material. Cooling and protection of bucket fixation are promising candidate measure to solve this task. External cooling of reheat section has been used in steam turbine design, and the cooling steam can be supplied from high pressure section. As is described in Fig. 7, the cooling steam flows into the space between inner casing and nozzle casing protecting outer surface of intermediate rotor and inner surface of inner casing. This external cooling makes it possible to apply New $12 \%$ Cr material to both rotor and inner casing. As for the bucket fixation, shank design can be used. This design provides two effects, one is to provide heat transfer surface for cooling steam, and the other is to provide heat resistance against heat conduction from steam path to fixation area. This design is very common in gas turbine design and can be applicable to steam turbine. If we compare conditions of gas turbine and intermediate pressure section of steam turbine, temperature is much higher for gas turbine, but pressures are close each other. This means that heat transfer coefficients, which plays an important role in cooling evaluation, are similar. This aspect will lead to higher reliability of cooling evaluation. As for the outer casing, conventional $\mathrm{Cr}-$ MoV cast steel can be applicable because high temperature steam is isolated due to the double pipe design at the inlet as was stated previously. In short, application of $\mathrm{Ni}$ base material is very limited, inner inlet pipe, nozzle casing, and shorter buckets, which is very advantageous for shorter research and development and smaller investment.

\section{Conclusions}

Experience of high temperature steam turbines was discussed focusing on design features. In particular, $700 \mathrm{MW}$ steam turbine with temperatures of 593/593 degree $\mathrm{C}$ is typical example that reflects recent research development, and was presented in detail. As far as further improvement of steam conditions is concerned, 630/700 degree $\mathrm{C}$ is very promising from the viewpoint of shorter research and development period considering material application and cooling design.

\section{References}

(1) Suzuki, A., Nomoto, H. and Kakishima, M., Development of a 700 MW Double Reheat Turbine with Advanced Supercritical Conditions, IMechE, C386/002, (1990), pp.31-37.

( 2 ) Mimuro, H. and Nomoto, H., The Development and the Operational Experience of the Steam Turbine with Advanced Steam Conditions, American Power Conference, April (1990).

(3) Shinozaki, Y., Kuroki, Y. and Yamaguchi, K., The Design of Large Steam Turbine with 600 C Class Steam Condition, Proceeding of the International Conference on Power Engineering-95, Vol.2, May (1995).

( 4 ) Hofer, D., Slepski, J., Tanuma, T., Shibagaki, T. and Tashima, T., Aerodynamic Design and Development of steel 48/40 Inch Steam Turbine LP End Bucket Series, Proceedings of International Conference on Power Engineering, Vol.2 (2003), pp.217-222. 